University of Warwick institutional repository: http://go.warwick.ac.uk/wrap

This paper is made available online in accordance with publisher policies.

Please scroll down to view the document itself. Please refer to the repository record for this item and our policy information available from the repository home page for further information.

To see the final version of this paper please visit the publisher's website. Access to the published version may require a subscription.

Author(s): Dunn J A, Kerr D J, Langman M J, Smith J L, Midgley R S, Stanley A, Stokes J C, Julier P, Iveson C, Duvvuri R, McConkey C C Article Title: Rofecoxib and cardiovascular adverse events in adjuvant treatment of colorectal cancer

Year of publication: 2007

Link to published version: http://dx.doi.org/10.1056/NEJMoa071841

Publisher statement: Not available online 


\title{
Rofecoxib and Cardiovascular Adverse Events in Adjuvant Treatment of Colorectal Cancer
}

\author{
David J. Kerr, M.D., Janet A. Dunn, Ph.D., Michael J. Langman, M.D., \\ Justine L. Smith, B.Sc., Rachel S.J. Midgley, M.D., Andrew Stanley, M.Phil., \\ Joanne C. Stokes, B.Sc., Patrick Julier, M.Sc., Claire Iveson, B.Sc., Ravi Duvvuri, B.Sc., \\ and Christopher C. McConkey, M.Sc., for the VICTOR Trial Group*
}

A B STRACT

From the Oncology Clinical Trials Office, University of Oxford, Oxford (D.J.K., J.L.S., R.S.J.M., J.C.S., P.J., C.I., R.D.); the Statistical Centre at Warwick Medical School Clinical Trials Unit, University of Warwick, Coventry (J.A.D., M.J.L., C.C.M.); and City Hospital, Birmingham (A.S.) - all in the United Kingdom. Address reprint requests to Dr. Kerr at the Department of Clinical Pharmacology, University of Oxford, Radcliffe Infirmary, Woodstock Rd., Oxford OX2 6HA, United Kingdom, or at david.kerr@clinpharm.ox.ac.uk.

* Members of the Vioxx in Colorectal Cancer Therapy: Definition of Optimal Regime (VICTOR) Trial Group are listed in the Appendix.

N Engl J Med 2007;357:360-9.

Copyright (C) 2007 Massachusetts Medical Society.

\section{BACKGROUND}

Selective cyclooxygenase inhibitors may retard the progression of cancer, but they have enhanced thrombotic potential. We report on cardiovascular adverse events in patients receiving rofecoxib to reduce rates of recurrence of colorectal cancer.

\section{METHODS}

All serious adverse events that were cardiovascular thrombotic events were reviewed in 2434 patients with stage II or III colorectal cancer participating in a randomized, placebo-controlled trial of rofecoxib, $25 \mathrm{mg}$ daily, started after potentially curative tumor resection and chemotherapy or radiotherapy as indicated. The trial was terminated prematurely owing to worldwide withdrawal of rofecoxib. To examine possible persistent risks, we examined cardiovascular thrombotic events reported up to 24 months after the trial was closed.

\section{RESULTS}

The median duration of active treatment was 7.4 months. The 1167 patients receiving rofecoxib and the 1160 patients receiving placebo were well matched, with a median follow-up period of 33.0 months (interquartile range, 27.6 to 40.1 ) and 33.4 months (27.7 to 40.4), respectively. Of the 23 confirmed cardiovascular thrombotic events, 16 occurred in the rofecoxib group during or within 14 days after the treatment period, with an estimated relative risk of 2.66 (from the Cox proportional-hazards model; 95\% confidence interval [CI], 1.03 to 6.86; $\mathrm{P}=0.04$ ). Analysis of the Antiplatelet Trialists' Collaboration end point (the combined incidence of death from cardiovascular, hemorrhagic, and unknown causes; of nonfatal myocardial infarction; and of nonfatal ischemic and hemorrhagic stroke) gave an unadjusted relative risk of 1.60 ( $95 \%$ CI, 0.57 to 4.51 ; $\mathrm{P}=0.37$ ). Fourteen more cardiovascular thrombotic events, six in the rofecoxib group, were reported within the 2 years after trial closure, with an overall unadjusted relative risk of 1.50 (95\% CI, 0.76 to 2.94; $\mathrm{P}=0.24$ ). Four patients in the rofecoxib group and two in the placebo group died from thrombotic causes during or within 14 days after the treatment period, and during the follow-up period, one patient in the rofecoxib group and five patients in the placebo group died from cardiovascular causes.

\section{CONCLUSIONS}

Rofecoxib therapy was associated with an increased frequency of adverse cardiovascular events among patients with a median study treatment of 7.4 months' duration. (Current Controlled Trials number, ISRCTN98278138.) 
PPROXIMATELY HALF OF ALL PATIENTS undergoing potentially curative surgery for colorectal cancer ultimately have a relapse and die of metastatic disease. This has led to the introduction of cytotoxic adjuvant therapy, ${ }^{1}$ the benefits of which are relatively small ( 5 to $10 \%$ improvement in the 5-year survival rate)..$^{2-4}$

A range of laboratory investigations suggest that cyclooxygenase-2 (COX-2) plays an important role in colorectal carcinogenesis during the transition from adenoma to carcinoma and subsequently during invasion and metastasis. ${ }^{5-7}$ Epidemiologic studies have indicated that the incidence of colorectal cancer is reduced by 30 to $70 \% \%^{8-10}$ in subjects taking nonsteroidal antiinflammatory drugs (NSAIDs). It has been hypothesized that the antineoplastic effects of NSAIDs are mediated by the inhibition of COX-2, and the gastrointestinal side effects of NSAIDs by the inhibition of COX-1, suggesting that any anticancer intervention involving selective COX-2 inhibitors, as compared with traditional NSAIDs, would reduce the risks of complications from peptic ulcer. ${ }^{11}$

Rofecoxib (Vioxx, Merck), a potent inhibitor of COX-2, was hypothesized to reduce rates of tumor recurrence in our randomized, placebocontrolled trial - the Vioxx in Colorectal Cancer Therapy: Definition of Optimal Regime (VICTOR) trial - of patients who had undergone potentially curative surgery for colorectal cancer. Recruitment for the VICTOR trial stopped in September 2004, when Merck withdrew the drug worldwide after a significant increase in confirmed cardiovascular thrombotic events was noted in the Adenomatous Polyp Prevention on Vioxx (APPROVe) trial. ${ }^{12}$ An excess of vascular events was then found in the Adenoma Prevention with Celecoxib (APC) polyp-prevention trial of celecoxib. ${ }^{13}$ Evidence from well-designed, randomized trials, and their meta-analysis, ${ }^{14}$ provides support for a moderate increase in vascular event rates associated with the use of COX-2 inhibitors, but there is less clarity about the duration of drug exposure that is responsible for the risk and whether it is equivalent in patients with and in those without established cancer, for whom the potential for benefit from reduced cancer progression may be large. In our study, we compared rates of cardiovascular thrombotic events and death during the period of study treatment and for 2 years after trial closure.

\section{METHODS}

\section{PATIENTS}

Patients were randomly assigned to receive rofecoxib or placebo at 151 hospitals in the United Kingdom. Inclusion criteria were as follows: histologically proven colorectal carcinoma of stage III (any tumor stage, N1 or 2, and M0) or stage II (T3 or 4, N0, and M0) in patients who had undergone complete resection of the primary tumor without gross or microscopical evidence of residual disease; World Health Organization performance status 0 or 1 ; and hematologic and biochemical function within the normal range. In addition, all patients had to have completed their potentially curative therapy (surgery alone or surgery plus radiotherapy, chemotherapy, or both) 12 or fewer weeks previously and had to have given written informed consent. Patients with active peptic ulceration or gastrointestinal bleeding in the past year, a history of adverse reactions to NSAIDs, or a known sensitivity to rofecoxib were excluded, as were those receiving long-term NSAID therapy (except for low-dose aspirin, $\leq 100 \mathrm{mg}$ per day), those younger than 18 years, and women who were pregnant, lactating, or premenopausal but not using contraception. Patients with a history of cancer (other than adequately treated in situ carcinoma of the cervix or basal or squamous-cell carcinoma), inflammatory bowel disease, or severe congestive heart failure were also excluded.

\section{TRIAL DESIGN}

We planned to randomly assign the use of rofecoxib (one 25-mg tablet daily) or placebo to 7000 patients, with half of each group receiving the study drug for 2 years and the other for 5 years, effectively a four-group design. Local investigators randomly assigned patients through the VICTOR Trial Office, and each patient was assigned to a study drug in a double-blind fashion. The VICTOR Trial Office supplied rofecoxib and placebo to participating hospitals every 6 months.

\section{PROTOCOL MODIFICATIONS}

Data-collection forms were amended in January 2004 (22 months into the trial) to solicit baseline data on cardiovascular risk factors, both for newly recruited patients and for patients already entered (Fig. 1 in the Supplementary Appendix, available with the full text of this article at www.nejm. 
org). Information sheets were amended twice to reflect evolving data on the possible adverse cardiovascular effects of rofecoxib. After the worldwide withdrawal of rofecoxib, all investigators and patients were informed, all study treatment was stopped, and follow-up was initiated.

\section{CARDIOVASCULAR EVENTS}

Blinded systematic review of all reported serious adverse events that were potentially cardiovascular thrombotic events and that were reported during treatment or within 14 days after the treatment period - the primary cardiovascular event end point - was conducted by an independent, expert physician panel selected from academic centers in the United States and Europe by Merck (Table 1 in the Supplementary Appendix). The use of published reporting systems $\mathrm{s}^{12,15}$ and adjudication by this previously assembled review panel allowed for consistency of adverse-event reporting across the placebo-controlled rofecoxib trials (VICTOR, APPROVe, and Vioxx in Prostate Cancer [VIP]), permitting a patient-level meta-analysis. Thrombotic events were defined as fatal and nonfatal myocardial infarction, unstable angina, sudden death from cardiac causes, fatal and nonfatal ischemic stroke, transient ischemic attack, peripheral arterial thrombosis, peripheral venous thrombosis, and pulmonary embolism. Also analyzed were serious adverse events meeting the Antiplatelet Trialists' Collaboration (APTC) criteria $^{15}$ : the combined incidence of death from cardiovascular, hemorrhagic, and unknown causes; of nonfatal myocardial infarction; and of nonfatal ischemic and hemorrhagic stroke. To avoid the possibility that censoring cardiovascular-event data 14 days after drug discontinuation, which was the approach used in the APPROVe trial, ${ }^{12}$ might distort the outcome data by ruling out later toxicity, further analysis was performed on all cardiovascular events that occurred during the treatment period or within 24 months after trial closure. These events were adjudicated by two of the authors. All patients who consented to inclusion in the study were registered centrally, and death certificates were automatically forwarded to the VICTOR Trial Office.

\section{ETHICS AND INDEMNITY}

Our study was designed by the investigators, and the protocol was peer reviewed and endorsed by the Clinical Trials Committee of the Cancer Re- search Campaign, the West Midlands Multicenter Research Ethics Committee, and local research ethics committees at participating centers. The trial was supported by an unrestricted grant from Merck, which also provided the rofecoxib and matching placebo and stood to provide indemnity but otherwise had no input into data accrual or data analysis or control over manuscript preparation. The randomization, data collection, monitoring, and follow-up were coordinated by the VICTOR Trial Office (initially located at the University of Birmingham and then relocated to the University of Oxford). Study data were analyzed by three of the authors at the Statistical Centre, University of Warwick, with an agreement to provide Merck with reports of serious adverse events that occurred after randomization and within 14 days after the end of the treatment period, as well as with a copy of the trial database at prespecified analysis points. An independent data and safety monitoring committee was appointed. Pharmacovigilance reports were reviewed by the Medicines and Healthcare Products Regulatory Agency (the U.K. regulatory authority) and by the West Midlands Multicenter Research Ethics Committee. All authors contributed to the writing of the manuscript, and the VICTOR Trial Office vouches for the accuracy and completeness of the data and analysis.

\section{STATISTICAL ANALYSIS}

Although our trial was not designed to analyze cardiovascular data, it had a statistical power of $90 \%$ to detect an increase by a factor of 2 in the overall risk of cardiovascular events, from 0.5 to $1 \%$, in patients taking rofecoxib for up to 2 years. The statistical power was insufficient for comparisons of risk according to duration of study treatment.

Kaplan-Meier curves were used to assess the time from the start of study treatment to the time of reporting of confirmed cardiovascular events (serious adverse events that were cardiovascular thrombotic events or Antiplatelet Trialists' Collaboration end points). Relative risks for confirmed cardiovascular events in the rofecoxib group, as compared with the placebo group, were calculated with the use of Cox proportionalhazards regression analysis, with study treatment as a factor. Relative risks were also adjusted according to age, use or nonuse of adjuvant chemotherapy, and presence or absence of cardiovascu- 
lar risk factors at baseline. All reported $\mathrm{P}$ values are two-sided, and $\mathrm{P}$ values less than 0.05 were considered to indicate statistical significance.

\section{RESULTS}

Between April 2002 and September 2004, a total of 2434 patients were recruited at 151 hospitals in the United Kingdom. One patient in the rofecoxib group was found to be ineligible because of an incomplete resection, and one patient in the placebo group was ineligible because random assignment took place more than 12 weeks after surgery. These patients were included in the analyses.

The intention-to-treat population comprised 1217 patients in the rofecoxib group and 1217 patients in the placebo group. Owing to an administrative error at a site pharmacy, one patient in the placebo group and one in the rofecoxib group received the incorrect medication for the first 6 months, and one patient in the rofecoxib group switched to placebo for a period of 3 weeks before switching back. Fifty patients in the rofecoxib group and 57 in the placebo group had not yet started the study treatment when rofecoxib was withdrawn. The intention-to-treat population included in analyses therefore comprised 1167 patients in the rofecoxib group and 1160 patients in the placebo group (Fig. 2 in the Supplementary Appendix). The duration of study treatment was known only approximately for 65 patients receiving rofecoxib and for 62 patients receiving placebo.

Table 1 shows that the assignment of study treatment was balanced on the basis of age, sex, disease site, cancer stage, and receipt or nonreceipt of previous adjuvant chemotherapy. The

\begin{tabular}{|c|c|c|c|}
\hline Characteristic & $\begin{array}{l}\text { Rofecoxib Group } \\
(\mathrm{N}=1167)\end{array}$ & $\begin{array}{l}\text { Placebo Group } \\
(\mathrm{N}=1160)\end{array}$ & P Value \\
\hline Stage of cancer - no. (\%) & & & 0.79 \\
\hline II & $551(47.2)$ & $554(47.8)$ & \\
\hline III & $616(52.8)$ & $606(52.2)$ & \\
\hline Site of cancer — no. (\%) & & & 0.46 \\
\hline Colon & $756(64.8)$ & $767(66.1)$ & \\
\hline Rectum and sigmoid colon & $93(8.0)$ & $77(6.6)$ & \\
\hline Rectum & $318(27.2)$ & $316(27.2)$ & \\
\hline Adjuvant chemotherapy — no. (\%) & $755(64.7)$ & $748(64.5)$ & 0.91 \\
\hline Age & & & 0.73 \\
\hline Median - yr & 65 & 65 & \\
\hline Interquartile range $-\mathrm{yr}$ & $58-71$ & $57-71$ & \\
\hline$<65 \mathrm{yr}-$ no. $(\%)$ & $574(49.2)$ & $579(49.9)$ & \\
\hline Male sex — no. (\%) & $745(63.8)$ & $742(64.0)$ & 0.95 \\
\hline White race - no. $(\%) *$ & $1147(98.3)$ & $1139(98.2)$ & 0.86 \\
\hline No history of hypertension — no. (\%) $†$ & $825(70.7)$ & $852(73.4)$ & 0.14 \\
\hline History of diabetes - no. (\%) $†$ & $102(8.7)$ & $65(5.6)$ & 0.003 \\
\hline No history of hyperlipidemia - no. (\%) $\ddagger$ & $601(51.5)$ & $588(50.7)$ & 0.70 \\
\hline Current smoker — no. (\%)』 & $141(12.1)$ & $129(11.1)$ & 0.47 \\
\hline History of symptomatic atherosclerotic disease - no. (\%) & $249(21.3)$ & $222(19.1)$ & 0.19 \\
\hline Low-dose aspirin use at baseline — no. (\%) & $101(8.7)$ & $80(6.9)$ & 0.11 \\
\hline
\end{tabular}

* Race was self-reported.

$\dagger$ The presence or absence of a history was unknown for three patients.

The presence or absence of a history of hyperlipidemia was unknown for 999 patients.

$\int$ The current smoking status was unknown for 20 patients.

I A history of symptomatic atherosclerotic disease was a composite measure defined as the presence of at least one risk factor in the "Documented History of Vascular Disease" section and at least two risk factors in the "Cardiac Risk Factors" section of the VICTOR Cardiovascular Risk Assessment Form (Fig. 2 in the Supplementary Appendix). 
risk-assessment forms were all received after randomization (half before the trial was unblinded), and it took approximately 18 months after trial closure to construct a validated database for analysis. Slightly more patients in the rofecoxib group than in the placebo group had predefined cardiovascular risk factors (Table 1). The median duration of trial treatment was 7.4 months (interquartile range, 3.1 to 14.0 ) in the rofecoxib group and 8.2 months (interquartile range, 3.7 to 15.0 ) in the placebo group, with $33 \%$ of all patients having received the study drug for at least 12 months (Table 2). The median duration of followup was 33.0 months (interquartile range, 27.6 to 40.1) in the rofecoxib group and 33.4 months (interquartile range, 27.7 to 40.4 ) in the placebo group.

Before the worldwide withdrawal of rofecoxib, 342 patients receiving rofecoxib and 268 patients receiving placebo discontinued the study drug before its intended completion, but all of these patients were included in the intention-to-treat population of 1167 patients in the rofecoxib group and 1160 patients in the placebo group. The most common medical reasons for early discontinuation of study drug were gastrointestinal pain or heartburn (15 patients in the rofecoxib group and 5 in the placebo group), analgesia required for arthritis (4 and 15, respectively), hypertension (7 and 1), renal impairment (7 and 1), diarrhea (4 and 4), and heart failure ( 2 in the rofecoxib

\begin{tabular}{|lcc|}
\hline \multicolumn{3}{|c|}{ Table 2. Reported Duration of Study Treatment.* } \\
\hline Rofecoxib \\
$\begin{array}{c}\text { Group } \\
\text { (N=1167) }\end{array}$ & $\begin{array}{c}\text { Placebo } \\
\text { Group } \\
\text { (N=1160) }\end{array}$ \\
$<30$ days (no.) & 112 & 72 \\
30 days to $<6$ mo (no.) & 381 & 368 \\
6 to $<12$ mo (no.) & 307 & 323 \\
12 to $<24$ mo (no.) & 321 & 348 \\
$\geq 24$ mo (no.) & 45 & 48 \\
Unknown (no.) & 1 & 1 \\
Median duration (days) & & \\
$\quad$ No. & 226 & 249 \\
$\quad$ Interquartile range & $94-425$ & $112-456$ \\
Total patient-yr & 889 & 946 \\
\hline
\end{tabular}

* The data include those for 65 patients in the rofecoxib group and 62 in the placebo group whose durations of study treatment were known only approximately. group). Since only $4 \%$ of patients received the study drug for more than 2 years, the randomization variable originally planned to reflect the duration of study treatment ( 2 years or 5 years) is unimportant.

Thirty-five potential cardiovascular thrombotic events occurring during or within 14 days after the treatment period were adjudicated in a blinded fashion by the independent panel convened by Merck (Table 1 in the Supplementary Appendix), including 11 events that were reported after the unblinding of study treatment in nine patients. Sixteen events in 15 patients receiving rofecoxib were confirmed to be cardiovascular thrombotic events, as compared with seven events in 6 patients receiving placebo. Three of these events occurred while the patients were taking other NSAIDs (sudden death from cardiac causes in a patient in the placebo group who was taking diclofenac, transient ischemic attack in a patient in the rofecoxib group who was taking diclofenac, and peripheral venous thrombosis in a patient in the rofecoxib group who was taking meloxicam). There were 10 events qualifying as an APTC end point in nine patients receiving rofecoxib, as compared with 6 events in six patients receiving placebo. Rates of confirmed cardiovascular thrombotic events per 100 patient-years are presented in Table 3 and in Kaplan-Meier plots in Figure 1. The median duration of study treatment before a cardiovascular event was reported was 157 days in the rofecoxib group and 195 days in the placebo group (Table 2 in the Supplementary Appendix). The relative risk of a cardiovascular thrombotic event during or within 14 days after the treatment period was 2.66 (95\% confidence interval [CI], 1.03 to 6.86 ) among patients receiving rofecoxib, as compared with those receiving placebo $(\mathrm{P}=0.04)$. The relative risk was slightly reduced after adjustment for cardiovascular risk factors (2.41; 95\% CI, 0.93 to $6.26 ; \mathrm{P}=0.07)$. Analysis of the APTC end points showed an unadjusted relative risk of 1.60 ( $95 \% \mathrm{CI}, 0.57$ to $4.51 ; \mathrm{P}=0.37$ ) and an adjusted relative risk of 1.42 (95\% CI, 0.50 to $4.03 ; \mathrm{P}=0.52$ ).

Further analysis, in which all cardiovascular events that occurred during the treatment period and all those reported within 24 months after trial closure were combined, was performed. An additional 14 cardiovascular events were noted (Table 3, and Table 2 in the Supplementary Appendix) after adjudication of all adverse events re- 


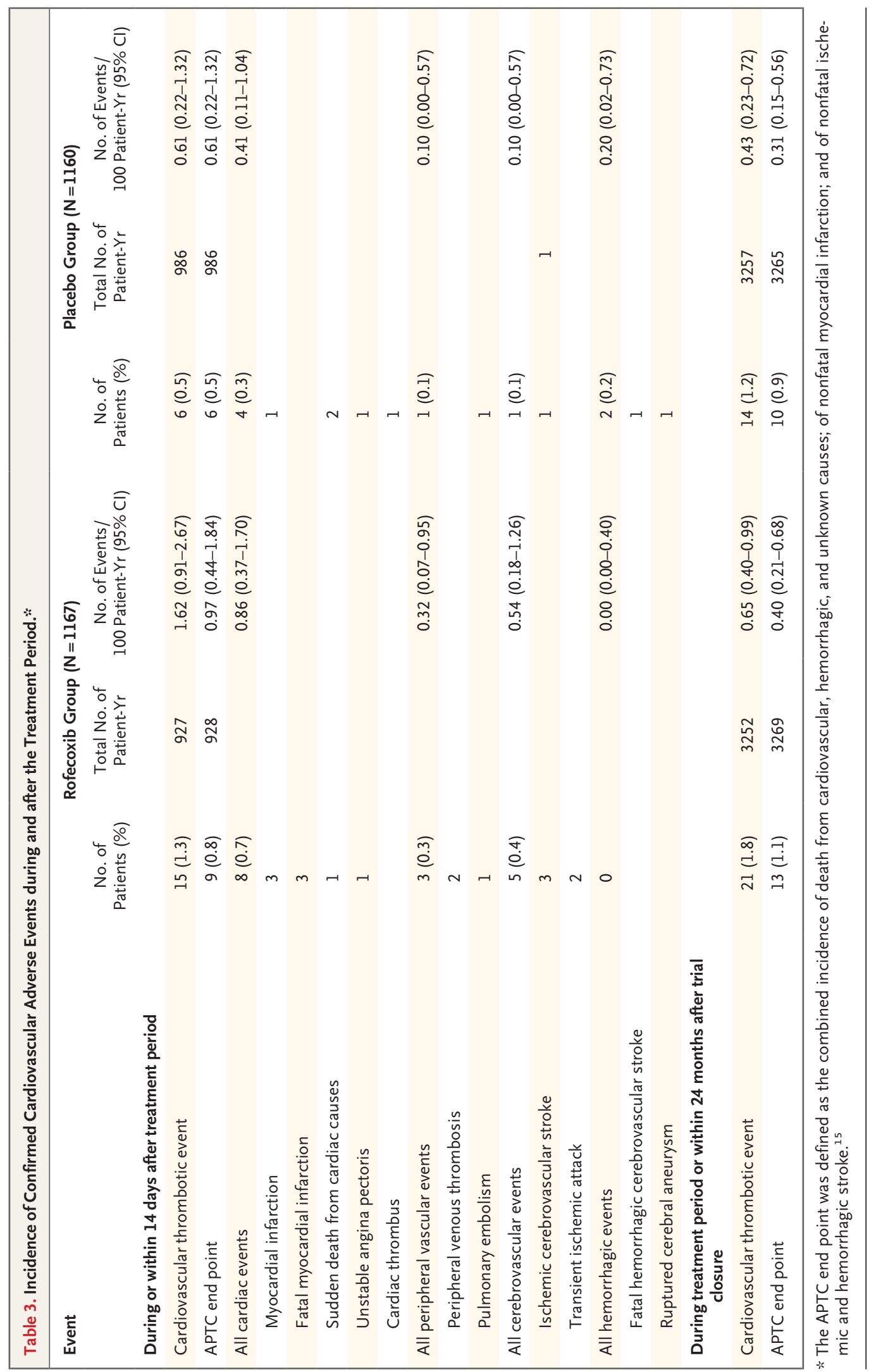




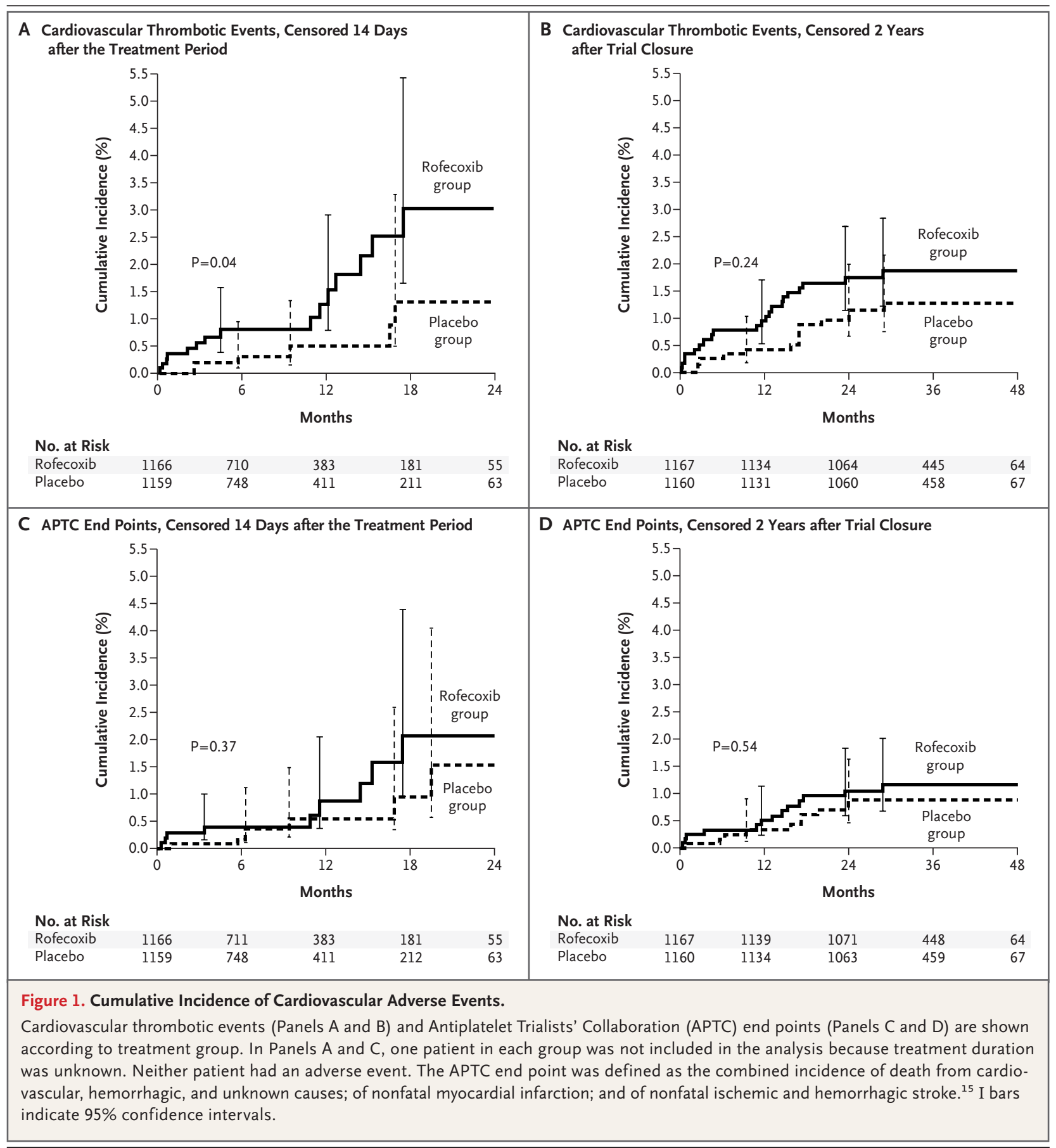

ported within 24 months after trial closure. The resulting relative risk of a cardiovascular thrombotic event, unadjusted for cardiovascular risk factors, was 1.50 ( $95 \% \mathrm{CI}, 0.76$ to $2.94 ; \mathrm{P}=0.24$ ). Analysis of the APTC end points showed an unadjusted relative risk of 1.29 (95\% CI, 0.57 to 2.95). Although information on blood pressure and renal function was not collected systematically, three patients in the rofecoxib group presented with congestive cardiac failure during the treatment period. Overall, four patients in the rofecoxib group and two in the placebo group died as a result of thrombotic events occurring during or within 14 days after the treatment period. An additional six deaths from cardiovascular thrombotic events (one patient in the rofecoxib group 
and five in the placebo group), identified by death certification, were reported within 24 months after trial closure. The total numbers of patients who died from cardiovascular causes - five in the rofecoxib group and seven in the placebo group - did not differ significantly.

\section{DISCUSSION}

The chief limitations of our study are the relatively small number of events available for analysis and the relatively short duration of exposure to the study drug (median, 7.4 months). However, our findings suggest an increased risk of a cardiovascular thrombotic event in patients randomly assigned to receive rofecoxib (as compared with those randomly assigned to receive placebo) as adjuvant treatment for the prevention of a recurrence of colorectal cancer (relative risk of an event during or within 14 days after the treatment period, 2.66; $95 \% \mathrm{CI}, 1.03$ to $6.86 ; \mathrm{P}=0.04$ ). These findings are consistent with those obtained in other placebo-controlled studies of treatment with COX-2 inhibitors in patients with colorectal adenoma. Extension of the period of observation of cardiovascular events to 24 months after trial closure did not show a statistically significant adverse effect of rofecoxib (relative risk, 1.50; 95\% CI, 0.76 to 2.94; $\mathrm{P}=0.24$ ). This information was generated by the serious-adverse-event reporting system that was maintained throughout the follow-up period and by central notification of death certification. It is possible that worldwide withdrawal of rofecoxib led to the underreporting of adverse events during the follow-up period.

Bresalier et al. ${ }^{12}$ reported results of the APPROVe trial, in which 2586 patients with a history of colorectal adenoma were randomly assigned to receive placebo or $25 \mathrm{mg}$ of rofecoxib daily (as in our study). The authors found an increased relative risk of cardiovascular thrombotic events in the rofecoxib group (1.92; 95\% CI, 1.19 to 3.11) and claimed that this risk was apparent after 18 months of treatment. Solomon et al. ${ }^{13}$ reviewed all potentially serious cardiovascular events in 2035 patients with a history of colorectal adenomatous polyps who had been enrolled in the APC study, which compared two doses of the selective COX-2 inhibitor celecoxib (200 mg or $400 \mathrm{mg}$ twice daily) with placebo. The composite end point of death from cardiovascular causes, myocardial infarction, stroke, or heart failure was more common in each of the celecoxib groups than in the placebo group (200-mg group: hazard ratio, 2.3; 95\% CI, 0.9 to 5.5; 400-mg group: hazard ratio, 3.4; 95\% CI, 1.4 to 7.8 ).

A recent meta-analysis of 138 randomized trials involving 145,373 participants assessed the risk of vascular events from the use of selective COX-2 inhibitors and traditional NSAIDs. ${ }^{14}$ In all, 121 placebo-controlled trials of selective COX-2 inhibitors (predominantly rofecoxib and celecoxib) were analyzed, and the authors found a proportional increase by nearly a factor of 2 in the risk of myocardial infarction among patients receiving COX-2 inhibitors as compared with placebo (hazard ratio, 1.86; 95\% CI, 1.33 to 2.59; $\mathrm{P}=0.003$ ) but no significant difference in the incidence of stroke. Too few vascular events were available to study the influence of dose, but the investigators noted that two thirds of the vascular events had occurred in the nine long-term trials with treatment periods of 1 year or more. It would appear from our study that patients taking rofecoxib for fewer than 18 months may be at increased risk for a cardiovascular thrombotic event, since $50 \%$ of all such reported episodes occurred in patients treated for fewer than 12 months. There has been a thorough statistical critique of the original interpretation of the timeto-event data of the APPROVe investigators, which has challenged their assessment of the data. ${ }^{16}$

Observational information, typically from the examination of large databases, suggests that treatment with COX-2 inhibitors may enhance cardiovascular risk and that such risk may be greater than, or the same as, that associated with the use of nonselective NSAIDs. ${ }^{17-19}$ A recent systematic review of observational data reported a dose-related relative risk of cardiovascular events of 1.33 (95\% CI, 0.91 to 1.23) with $25 \mathrm{mg}$ of rofecoxib per day or less, as compared with placebo, and a relative risk of 2.19 (95\% CI, 1.64 to 2.91) with more than $25 \mathrm{mg}$ of rofecoxib per day. ${ }^{20}$ The ability of population-based studies to give definitive answers is inevitably limited because of the difficulty in controlling for confounders; however, the summary relative risk in the systematic review ${ }^{20}$ is similar to that found in the meta-analysis of randomized trials. ${ }^{14} \mathrm{~A}$ recent report from the European Medicines Agency ${ }^{21}$ concluded that epidemiologic evidence and updated trial data continue to point to an increased thrombotic risk with COX-2 inhibitors, possibly 
accounting for about three events per 1000 patientyears.

The mechanism linking the use of COX-2 inhibitors to an increased incidence of thrombotic vascular events has not been precisely elucidated. Cyclooxygenase and its prostanoid products have important roles in regulating factors affecting the risk of thrombosis; for instance, thromboxane synthase is regulated by COX-2. It is generally accepted that patients with cancer have a higher risk of thrombosis than does the general population, and a positive correlation has been found between increased expression of thromboxane synthase and shortened survival from bladder cancer. ${ }^{22}$ Current data are insufficiently mature to permit commentary on the risks of recurrence of or death from cancer, but prolonged follow-up will provide more informative data.

Sponsored by the University of Oxford and an educational study grant from Merck.

Drs. Kerr and Dunn report receiving grant support from Cancer Research UK; Dr. Dunn, receiving consulting fees from Merck and Johnson \& Johnson; and Dr. Langman, serving as an advisor to Merck and to Novartis and as a consultant to lawyers representing Merck. No other potential conflict of interest relevant to this article was reported.

We thank the VICTOR trial staff (F. Duchesne, K. Reed, S. Pendlebury, I. Kennedy, G. Davis, J. Birtwistle, L. Blair, A. Bange, K. Bell, L. Dunham, R. Deacon, A. Mellor, and B. Mikolajczyk); the clinical coordinators (S. Grumett and D. Rea); the VICTOR Trial Advisory Group; the U.K. National Cancer Research Institute and Cancer Research Campaign Clinical Trials Awards and Advisory Committee for permitting the support from the U.K. National Cancer Research Network; and all the nurses, clinicians, and patients who participated in this trial.

Members of the VICTOR trial were as follows. Independent Data and Safety Monitoring Committee: Finsen Institute, Copenhagen - H.H. Hansen; Centre for Statistics in Medicine, Oxford, United Kingdom — D. Altman; Churchill Hospital, Oxford, United Kingdom — D. Talbot; Principal investigators: Mayday University Hospital — M. Abulafi; North Staffordshire Royal Infirmary — F. Adab; Queen Elizabeth Hospital King's Lynn A. Ahmad; St. James University Hospital - S. Ambrose; Wexham Park Hospital — R. Ashford; Singleton Hospital — C. Askill; North Tyneside General Hospital - P. Atherton; Royal Shrewsbury Hospital — S. Awwad; South Tyneside District Hospital — A. Azzabi; Torbay Hospital — N. Bailey; Withybush General Hospital — A. Barnes; St. Mary's Hospital Newport — C. Baughan; Beesley Conquest Hospital — S. Harriet; Gloucester Royal Hospital - K. Benstead; Nottingham City Hospital — E. Bessell; Great Western Hospital — C. Blesing; Bradford Royal Infirmary — C. Bradley; Royal Gwent Hospital — A. Brewster; North Middlesex University Hospital — J. Bridgewater; Macclesfield District General Hospital — W. Brough; Norfolk \& Norwich University Hospital — A. Bulman; Glasgow Royal Infirmary and Western Infirmary — J. Cassidy; Derbyshire Royal Infirmary - P.R. Chakraborti; Kidderminster Hospital - M. Churn; St. Mary's Hospital London - S. Cleator; Pinderfields General Hospital - R. Cooper; Addenbrooke's Hospital — P. Corrie; Newcastle General Hospital - F. Coxon; Airedale General Hospital — M. Crawford; Princess Royal Hospital - A. Crawshaw; Royal Glamorgan Hospital — T. Crosby; Royal Marsden Hospital Sutton — D. Cunningham; Derriford Hospital — F. Daniel; Wansbeck General Hospital — W. Dobrowsky; Belfast City Hospital — M. Eatock; Royal Cornwall Hospital — R. Ellis; Lincoln County Hospital — J. Eremin; Yeovil District Hospital — S. Falk; Worcester Royal Hospital — D. Farrugia; Russells Hall Hospital — D. Ferry; Leeds General Infirmary - P. Finan; Countess of Chester Hospital - G. Foster; Royal Berkshire Hospital — A. Freebairn; Birmingham Heartlands Hospital I. Geh; Oldchurch Hospital — A. Gershuny; Royal United Hospital Bath — E. Gilby; Good Hope Hospital — J. Glaholm; Mount Vernon Hospital - R. Glynne-Jones; Glan Clwyd Hospital — S. Gollins; Princess Elizabeth Hospital Guernsey - P. Gomes; Walsgrave Hospital - R. Grieve; Darlington Memorial Hospital — K. Gunning; Royal Hampshire County Hospital - V. Hall; Manor Hospital - A. Hartley; Poole Hospital — T. Hickish; Maidstone Hospital — M. Hill; Manchester Royal Infirmary — J. Hill; Royal Sussex County Hospital — N. Hodson; Weston Park Hospital — J. Hornbuckle; Salisbury District Hospital — T. Iveson; Bronglais General Hospital — D. Jackson; Huddersfield Royal Infirmary — J. Joffe; Warwick Hospital — D. Jones; Leicester Royal Infirmary — S. Khanna; Whittington Hospital — J. Ledermann; St. Thomas' Hospital — M. Leslie; Royal Bolton Hospital — E. Levine; St. George's Hospital — F. Lofts; Leighton Hospital — J. Logue; Diana Princess of Wales Hospital — P. Mack; Luton \& Dunstable Hospital - A. Makris; Whiston Hospital - E. Marshall; Velindre Hospital — T. Maughan; Trafford General Hospital — F. Mazarelo; Peterborough District Hospital — K. McAdam; Eastbourne District General Hospital — F. McKinna; Royal Free Hospital — T. Meyer; Worthing Hospital — T. Miles; Castle Hill Hospital — J. Monson; West Suffolk Hospital — M. Moody; Ninewells Hospital — A. Munro; North Devon District Hospital — M. Napier; Cumberland Infirmary — J. Nicoll; Northwick Park Hospital — J. Northover; St. Mary's Hospital Portsmouth — A. O'Callaghan; Milton Keynes General Hospital — R. O'Hara; Dorset County Hospital — R. Osbourne; Sunderland Royal Hospital — I. Pedley; Charing Cross Hospital - R.H. Phillips; Western General Hospital - H. Phillips; Epsom General Hospital — M. Raja; Pennine Acute Hospitals National Health Service Trust — A. Rate; City Hospital — D. Rea; Southern General Hospital — G. Robertson; Southend Hospital — A. Robinson; Hope Hospital — M. Saunders; York District Hospital — D. Sebag-Montefiore; Cookridge Hospital — M. Seymour; Ipswich Hospital National Health Service Trust - K. Sherwin; Tameside General Hospital — K. Siddiqui; University Hospital Aintree — D. Smith; Pontefract General Infirmary — M. Snee; King George Hospital — S. Snooks; Alexandra Hospital — S. Sothi; Scunthorpe General Hospital — T. Sreenivasan; Noble's Hospital S. Stock; Ysbyty Gwynedd — N. Stuart; Southport \& Formby District General Hospital — A. Sun-Myint; University Hospital Hartlepool — M. Tabaqchali; University Hospital of North Tees - M. Tabaqchali; Broomfield Hospital — S. Tahir; Hinchingbrooke Hospital — L.T. Tan; Bedford General Hospital — R. Thomas; Halton Hospital — M. Tighe; Taunton \& Somerset Hospital — M. Tighe; Weston General Hospital — M. Tomlinson; Royal Surrey County Hospital — C. Topham; Friarage Hospital — J.C.M. Van der Voet; James Cook University Hospital — N. Wadd; Stoke Mandeville Hospital — N. Warner; Hammersmith Hospital — H. Wasan; Royal Liverpool University Hospital — A. Watson; Churchill Hospital — A. Weaver; St. Bartholomew's Hospital — P. Wells; Stepping Hill Hospital - P. Wilkinson; Withington Hospital — M. Wilson; Royal Albert Edward Infirmary — G. Wilson; George Eliot Hospital — J. Worlding; Hairmyres Hospital — H. Yosef; Queen Elizabeth Hospital London — C.-Y. Yui. 
REFERENCES

1. Midgley RS, Kerr DJ. ABC of colorectal cancer: adjuvant therapy. BMJ 2000; 321:1208-11.

2. QUASAR Collaborative Group. Comparison of fluorouracil with additional levamisole, higher-dose folinic acid, or both, as adjuvant chemotherapy for colorectal cancer: a randomised trial. Lancet 2000;355:1588-96.

3. QUASAR Collaborative. QUASAR: a randomized study of adjuvant chemotherapy (CT) vs observation including 3238 colorectal cancer patients. J Clin Onco 2004;22:Suppl 14:3501a. abstract.

4. Sargent DJ, Wieand HS, Haller DG, et al. Disease-free survival versus overall survival as a primary end point of adjuvant colon cancer studies: individual patient data from 20,898 patients on 18 randomised trials. J Clin Oncol 2005;23:8664-70.

5. Oshima M, Murai N, Kargman S, et al. Chemoprevention of intestinal polyposis in the Apcdelta716 mouse by rofecoxib, a specific cycooxygenase-2 inhibitor. Cancer Res 2001;61:1733-40.

6. Sheehan KM, Sheahan K, O'Donoghue DP, et al. The relationship between cyclooxygenase-2 expression and colorectal cancer. JAMA 1999;282:1254-7. [Erratum, JAMA 2000;283:1427.]

7. Fenwick SW, Toogood GJ, Lodge PA, Hull MA. The effect of the selective cyclooxygenase-2 inhibitor rofecoxib on human colorectal cancer liver metastases. Gastroenterology 2003;125:716-29.

8. Giovannucci E, Rimm EG, Stampfer MJ, Colditz GA, Ascherio A, Willett WC. Aspirin use and the risk of colorectal cancer and adenoma in male health professionals. Ann Intern Med 1994;121:241-6.
9. Thun MJ, Namboodiri MM, Calle EE, Flanders DW, Heath CW Jr. Aspirin use and risk of fatal cancer. Cancer Res 1993;53: 1322-7.

10. Langman MJS, Cheng KK, Gilman EA, Lancashire RJ. Effect of anti-inflammatory drugs on overall risk of common cancer: case-control study in general practice research database. BMJ 2000;320: 1642-6.

11. Langman MJ, Jensen DM, Watson DJ, et al. Adverse upper gastrointestinal effects of rofecoxib compared with NSAIDs. JAMA 1999;282:1929-33.

12. Bresalier RS, Sandler RS, Quan H, et al. Cardiovascular events associated with rofecoxib in a colorectal adenoma chemoprevention trial. N Engl J Med 2005;352: 1092-102. [Erratum, N Engl J Med 2006; 355:221.]

13. Solomon SD, McMurray JJV, Pfeffer MA, et al. Cardiovascular risk associated with celecoxib in a clinical trial for colorectal adenoma prevention. $\mathrm{N}$ Engl J Med 2005;352:1071-80.

14. Kearney PM, Baigent C, Goodwin J, Halla H, Emberson JR, Patrono C. Do selective cyclo-oxygenase-2 inhibitors and traditional non-steroidal anti-inflammatory drugs increase the risk of atherothrombosis? Meta-analysis of randomised trials. BMJ 2006;332:1302-5.

15. Antiplatelet Trialists' Collaboration. Collaborative overview of randomised trials of antiplatelet therapy. I. Prevention of death, myocardial infarction, and stroke by prolonged antiplatelet therapy in various categories of patients. BMJ 1994;308:81-106. [Erratum, BMJ 1994;308: 1540.]
16. Lagakos SW. Time-to-event analyses for long-term treatments - the APPROVe trial. N Engl J Med 2006;355:113-7.

17. Johnsen SP, Larsson H, Tarone RE, et al. Risk of hospitalization for myocardial infarction among users of rofecoxib, celecoxib, and other NSAIDs: a populationbased case-control study. Arch Intern Med 2005;165:978-84.

18. Mamdani M, Rochon P, Juurlink DN, et al. Effect of selective cyclooxygenase 2 inhibitors and naproxen on short-term risk of acute myocardial infarction in the elderly. Arch Intern Med 2003;163:481-6.

19. Andersohn F, Suissa S, Garbe E. Use of first- and second-generation cyclooxygenase-2-selective drugs and risk of acute myocardial infarction. Circulation 2006; 113:1950-7.

20. McGettigan P, Henry D. Cardiovascular risk and inhibition of cyclooxygenase: a systematic review of observational studies of selective and nonselective inhibitors of cyclooxygenase 2. JAMA 2006;296: 1633-44.

21. Public CHMP assessment report for medicinal products containing non-selective non-steroidal anti-inflammatory drugs (NSAIDs). London: European Medicines Agency, November 7, 2006. (Accessed July 2, 2007, at http://www.emea.europa.eu/ pdfs/human/opiniongen/44213006en. pdf.)

22. Moussa O, Yordy JS, Abol-Enein H, et al. Prognostic and functional significance of thromboxane synthase gene overexpression in invasive bladder cancer. Cancer Res 2005;65:11581-7.

Copyright (c) 2007 Massachusetts Medical Society. 